\title{
Providing Aged Care: The Case for Reform
}

\author{
Henry Ergas ${ }^{1}$
}

\begin{abstract}
In the years ahead, the demand for aged care will polarise between community-based care and high-care facilities. The deregulation of current restrictions on the number of residential aged-care places, accompanied by the use of competitively neutral and fully portable vouchers for users of aged care, would help the sector adjust to these changes. Price regulation should be gradually reduced, contingent on the development of increased competition in the sector.
\end{abstract}

\section{Introduction}

Australia faces many challenges associated with the provision and financing of aged care in the coming years. This article examines a number of these challenges and proposes reforms to the current regulatory and policy framework underlying the aged-care sector. Two theses are advanced:

- First, due to recent demographic developments, the demand for aged care will polarise towards community-based care on the one hand and high-care facilities on the other.

- Second, that the best means of dealing with the challenges posed by this change in demand is by reducing current regulatory constraints on supply; that is, through deregulating the number of aged-care places, combined with the use of a portable and competitively neutral funding mechanism for users of aged care. Contingent on the development of increased competition in the sector, current price regulation could and should then be gradually wound back.

The analysis begins with an overview of the regulatory and other policy constraints imposed on the aged-care sector in Australia. It then details emerging demographic trends and the pressures these will place on supply of places in the aged-care sector, before setting out a proposed means of addressing these pressures through a phased program of deregulation.

\footnotetext{
${ }^{1}$ Concept Economics, HenryErgas@concepteconomics.com.au. I am very grateful to Dr David Cullen, of the Department of Health and Ageing, for his advice and assistance. I am also grateful to Jason Soon for research assistance and to the Editor for very helpful comments. The views expressed here, however, are entirely my own and I take full responsibility for any errors.
} 


\section{The Present Regulation of aged care}

The provision of aged-care services has the following important characteristics (Productivity Commission 2008):

- The production of 'bundles' of services tailored to a wide variety of individual needs, ranging from personal-care services to accommodation and palliative care;

- A high degree of direct contact between providers and clients, as opposed to arm's-length market transactions;

- A significant variation in the cost of service provision, with some services being much higher cost than others; and

- High, and increasing, community expectations about the provision of these services.

Reflecting these characteristics, governments typically play a significant role in the aged-care services industry. That said, compared with governments abroad, Australian governments have a particularly high degree of direct involvement in controlling the financing and supply of aged-care services.

Thus, Australian governments - and the Commonwealth Government in particular — bear the primary burden of funding residential aged care. ${ }^{2}$ The Commonwealth also funds community care, which provides care in the home, but currently shares that responsibility with the States.

Additionally, the Commonwealth extensively regulates care provision. That regulation extends not only to ensuring service quality, but also to controlling the number, composition and location of the places made available. More specifically, the Commonwealth uses 'planning ratios' that specify the number of aged-care places that are to be made available as a function of the population aged 70 and over. ${ }^{3}$ Access to these places is controlled through a process of needs assessment, based on medical evaluations of disability that grade potential

\footnotetext{
2 It currently costs about $\$ 65,000$ per person per year to provide high-level residential aged care. The Commonwealth Government meets almost three-quarters (72 per cent) of this cost. Annual costs in low-level residential aged care are lower (at just under $\$ 40,000$ per person per year), with just under 50 per cent of that cost being covered by the Commonwealth (unpublished data for 2007-08 provided by the Australian Department of Health and Ageing).

3 The planning arrangements, which specify the number and location of places, have been in operation since 1985. The number of subsidised residential aged-care places is currently capped at 88 operational places for every 1000 people aged at least 70. The supply of service type within this overall cap is also controlled, so that 44 of every 88 places are primarily for care recipients who require residential high care on entry to care and 44 are primarily for care recipients who require residential low care on entry to care. Actual service provision ratios differ from these planning targets, largely because of the policy of 'ageing in place', which allows a resident who enters a low-care place for low care to remain in that place if and when he or she comes to need and receive high care. Reflecting that policy, around 61 of every 88 places are used for high care, with the remaining 27 places used for low care. See Australian Department of Health and Ageing 2009a.
} 
beneficiaries in terms of the degree of care that they require. ${ }^{4}$ Through these controls over numbers, the Commonwealth rations the use of the service, thus controlling its fiscal exposure.

The Commonwealth also regulates the prices that aged-care providers can levy on their residents. While the costs incurred by around a third of residents are borne entirely by the Commonwealth (other than the basic daily fee of 85 per cent of the age pension, which is arguably a transfer payment by the Commonwealth), the vast majority of residents pay some part of the charges associated with these regulated prices, with the extent of this co-payment depending on highly complicated and somewhat opaque income and assets tests.

Historically, Commonwealth involvement in the funding of aged care arose at the intersection of the pension (and, more generally, income support) and health-care systems. From the former, it inherited an emphasis on means-testing, which is complex and extensive for residential care. From the latter came an emphasis on universality of access, tempered by quantity rationing (enforced through the restrictions on the number of places) and by reliance on significant co-payments (Cullen 2003).

At the moment, long-term aged-care services are provided in three forms which broadly correspond to differing levels of acuity:

- domiciliary care (also known as 'community care'), which mainly responds to situations where the need for care is relatively limited, though domiciliary care is increasingly being provided for relatively care-intensive situations, notably dementia;

- 'low care' residential care, also referred to as 'care in a hostel'; and

- 'high care' or nursing-home residential care, which addresses cases where a high level of ongoing nursing or intensive personal care is required.

It is residential care ('high care' and 'low care' aggregated) which has accounted for the bulk of (public and private) aged-care outlays (83 per cent). 'High care' in particular accounted for 65 per cent of residents and 78 per cent of public and private residential care outlays in 2004-05.

These three forms of care define a notional continuum, in which care recipients move, as their ability to cope with the activities of daily living diminishes, from limited domiciliary care, to 'low care' residential care and then on (though often for very short periods of time) to 'high care'. This progression reflects the underlying economics of care provision: domiciliary care allows care recipients to retain the comfort of their own home, but imposes transport costs on non co-resident carers and forgoes scale and scope economies in the supply of care;

\footnotetext{
4 This assessment is currently done by Aged Care Assessment Teams (ACAT), which are funded by the Commonwealth Government but managed by State Governments.
} 
in contrast, residential care secures economies in specialised infrastructure (including accommodation that is purpose-designed in terms of mobility and safety) and in the use of specialised resources (such as nursing staff), but at the cost of standardised accommodation arrangements and loss of close contact with the external community. As higher levels of disability require ever more use of the specialised inputs, relative to more general inputs such as conventional accommodation, it is generally cost-effective to provide the more intense levels of care in a specialised residential-care environment.

Whether movement along this continuum will remain as a general trend is, however, questionable, as the following section explains.

\section{Recent trends and approaching challenges}

On current demographic projections, the number of Australians aged 85 and over will increase from 330000 in 2006 to 580000 in 2021, and then to over 1.6 million in 2051. ${ }^{5}$ Underlying this trend are changes in life expectancy at the conventional retirement age of 65. As shown in Table 1, in 1983, life expectancy at age 65 stood at 14 years for men and 18 years for women. By 2001-3, life expectancy had increased to 18 years for men and 21 years for women. It is expected to have increased further to 21 years for men and close to 24 years for women by 2021. Reflecting this increase in life expectancy after age 65, the number of the very elderly is expected to rise especially sharply, in the context of a population which, as a whole, is becoming more concentrated in the older age brackets.

Table 1: Life expectancy at age 65 (years)

\begin{tabular}{|l|l|l|l|}
\hline & 1983 & $2001-3$ & 2021 \\
\hline Men & 14 & 18 & 21 \\
\hline Women & 18 & 21 & 24 \\
\hline
\end{tabular}

As that process occurs, the challenge of providing long-term care ${ }^{6}$ of and to the elderly will become of increasing importance. It is obvious that the need for some form of assistance with everyday activities increases with age. For instance, in 2003, 32 per cent of those aged 65-74 years needed some form of assistance, compared with around 86 per cent of those aged 85 or older (Productivity Commission 2008: 9).

Reflecting this, the ageing of the population will require increased spending, be it public or private, on aged-care services. As shown in Table 2, the federal government's consultative body, the National Health and Hospitals Reform Commission, has estimated that 337500 aged-care places will be needed by 2020,

\footnotetext{
5 These estimates are from the Australian Bureau of Statistics: see Linacre 2006.

6 'Long-term care' refers to care provided for the treatment of chronic conditions, where the emphasis is on care rather than cure. While long-term care is required for many disabilities, the focus here is on the management of those chronic conditions associated with ageing.
} 
while 464000 places will be needed by 2030, representing an increase of 108 per cent over the June 2008 level (NHHRC 2009: 165).

Table 2: Expected growth in required aged care places, for 2020 and 2030

\begin{tabular}{|l|l|l|}
\hline & 2020 & 2030 \\
\hline Aged care places required & 337,500 & 464,000 \\
\hline $\begin{array}{l}\text { Increase in places required over June 2008 } \\
\text { levels }\end{array}$ & $51 \%$ & $108 \%$ \\
\hline
\end{tabular}

Two other developments add to these challenges. The first is 'the old' are living longer than ever before, with a rise in the numbers expected to live beyond the age of 70 and hence to be at greater risk of requiring care. ${ }^{7}$ The second is that younger cohorts are having fewer children, ${ }^{8}$ which among other things means they will have fewer voluntary carers to draw on when they reach old age. These trends alone - the sheer increase in the numbers of the very old, especially relative to the potential population of carers - make large and sustained increases in the demand for aged care inevitable.

The impacts on the structure of demand for care are also important, though more complex.

On the one hand, smaller differences in life expectancy between men and women $^{9}$ may reduce the demand for residential care as they translate into fewer years of widowhood - since loss of a family care-giver often precipitates a need for residential care. ${ }^{10}$ This effect, which is partially offset by the increase in the number of persons who have never married or who are divorced or separated (Australian Bureau of Statistics 2007), may be accentuated by improved health among the 'younger elderly',' as well as by the likely strong aversion of the 'baby-boomers' to institutionalised living and institutional forms of care. ${ }^{12}$

\footnotetext{
${ }^{7}$ More than half (51.4 per cent) of all women aged 70 and more than one-third (34.1 per cent) of all men aged 70 will require permanent residential aged care at some time in their remaining life. By age 85 these probabilities have grown to almost two-thirds (62.5 per cent) and almost one-half ( 45.6 per cent) respectively. See Cullen 2007.

${ }^{8}$ See Productivity Commission 2008: 34 for a summary of this trend, and Australian Government 2007.

9 The diminished gap between male and female life expectancy translates into a changing male to female ratio in the older population. For the population aged 65 and over, there were 73.4 males per 100 females in 1987; by 2007, the ratio had increased to 82.6 males per 100 female. However, the difference in life expectancy for the very old population remains significant, with the ratio for those aged 85 and over being of 49.5 males per 100 females in 2007 based on analysis of Australian Bureau of Statistics (2008a, Cat.No.3105.0.65.001, Table 4.1).

${ }^{10}$ The impact of differential mortality on demand for long-term care is examined in Lakdawalla and Philipson 2002; and Lakdawalla and Schoeni 2003.

11 Today, the 'younger elderly' or 'younger old' are perhaps most commonly defined as those between 65 and 74, with the 'older elderly' being older than this (see, for example, Alexander, K. et al. 2001). However, viewed more broadly, 'younger old' refers to people who once were considered old, but who broadly remain, as a group, much more like non-old people of previous generations. As a result, the age group of the younger old has risen over time and likely will continue to do so.

12 See McCallum 2003 for evidence that almost 60 per cent of people aged 70 years or over would prefer to receive formal care in their own home in the event they were unable to care for themselves, compared to 28 per cent who would prefer to receive residential care. Productivity Commission 2008: 53 cites
} 
On the other hand, the growth in numbers in the very elderly age brackets is likely to be associated with increased numbers of sufferers from dementia, extreme fragility and other serious impairments to daily living activities, all of which usually require some form of intensive residential care. ${ }^{13}$ More generally, while there will be a significant increase in the average number of years a person lives in the age brackets 65 and above, it will continue to be the case that ageing will bring with it associated health problems (US National Institute on Aging, National Institutes of Health 2002 and Gillick 2006: 124ff). These age-related pathologies will be accentuated by the rising population incidence of chronic conditions such as obesity, which appear more likely to give rise to increased morbidity in the older population than to increased mortality. ${ }^{14}$ These factors will translate into a requirement for substantial, ongoing and continuous assistance, usually involving residential care, especially for the 'older old'.

The overall result seems likely to be to create a growing need for two types of care provision.

The first is care that is provided in a person's home, including in congregated living arrangements - such as life care communities - that seek to integrate home and care. This type of care, which corresponds to the various forms of community care, should suffice for the growing numbers who have a reasonable, even if incomplete, ability to carry out basic daily activities, especially in circumstances where they also have spousal or family assistance. The strong preference of the 'baby-boom' generation for independent living is likely to make this kind of domiciliary care the option of choice for large sections of the aged population.

The second is care in residential facilities that provide for those who have little or very little ability to undertake basic daily-living activities, and who need a high level of close support - as in current 'high care'. Demand for this kind of care will rise as we experience a continued increase in the incidence of those chronic conditions - such as Alzheimer's disease, severe arthritis and serious visual and hearing impairment - that reduce, if they do not eliminate, the ability to live without continuous assistance.

Conversely, demand for residential 'low care', which is intermediate between home care and ongoing close support, may decline as a proportion of total long-term care as the 'baby-boom' generations come into old age. 'Low care' facilities will, of course, remain of importance, if nothing else because the sheer

\footnotetext{
results of a recent survey conducted by Fujitsu Australia and New Zealand of 58 to 61 year olds, which found that four out of five respondents indicated a high or very high preference for independent living. ${ }^{13}$ The prevalence of dementia, for example, appears to double every five years after age 65. As a result, if current age-specific dementia rates remain unchanged, the prevalence of dementia will double by 2030 (Henderson and Jorm 1998).

${ }^{14}$ See Reynolds, Saito and Crimmins 2005. According to the Australian Institute of Health and Welfare, the prevalence of obesity has been rising in Australia over at least the past 20 to 30 years.
} 
scale of the increase in the older population will ensure continued substantial demand for residential facilities oriented to low, but not insignificant, levels of disability. Moreover, the demand for intermittent residential care services, again oriented to relatively low levels of disability, is also likely to increase substantially. ${ }^{15}$ This kind of care will in many instances be provided in a low care' setting. But while these factors will ensure that 'low care' remains significant in absolute terms, its weight in the overall structure of care provision seems set to diminish.

In short, demand for care is likely to shift from being a continuum that moves from home, into low-level care and then (often for only a short time) into high-level care, towards a pattern concentrated at the two ends of the spectrum.

At the same time, the temporal structure of care - that is, the distribution of durations of care in the recipient population - is likely to change.

Thus, long durations are likely to become more common in high-level care, as that care becomes less of an immediate antecedent to death. Already, at all levels of frailty, residents with dementia remain in residential care for significantly longer than other residents (Lindsay et al. 2003). Over the last four years, the proportion of discharges from permanent residential care that were in care for at least two years after admission has risen by 1.9 percentage points (from 38.6 per cent to 40.5 per cent).

However, short stays are also common. In the last three months of 2006, for example, 10.9 per cent of discharges from high-level residential care occurred less than one month after admission, and 12.2 per cent of discharges occurred between one to three months after admission (with 70 per cent and 69.8 per cent, respectively, of these discharges being due to death). These short stays are likely to remain common, and indeed may become more so, both because of the greater prevalence of intermittent care and because many admissions continue to be as a result of acute events.

As a result, the distribution of durations of residential care, which already is bimodal, ${ }^{16}$ may become even more so, with a bunching of durations at the relatively short and relatively long ends of the duration spectrum.

\footnotetext{
15 Older people living in the community at times require additional assistance, including residential care, for short periods. This may be to allow carers to take holidays or otherwise temporarily reduce their load. Providing more services such as respite care (that is, temporary accommodation in a residential-care facility aimed at relieving the carer) will allow more older people to stay in, or return to, the community after a period of more intense care. As a result, provision of facilities for respite care is an important complementary element in a strategy aimed at facilitating primary reliance on community care. Another instance in which people receiving care in their own home may need to access more intensive residential services is as a substitute for a medical admission to hospital (for example, for influenza).

16 See, for example, Xie, Chaussalet and Millard 2005.
} 
These changes in the level, structure and duration of demand will impose a significant adjustment burden on the aged-care sector. The total supply of care will need to increase, with large absolute rises being required in the level of provision in each part of the aged-care spectrum. For example, for current ratios of places available to the aged population to be met in 2025, an absolute increase of 83100 places would be required in low care (as compared to a total number of low-care places of 86000 today), with the corresponding increase in high care being of 87400 places (as compared to a total number of high-care places of 81 700 today). At the same time, the structure of supply will need to shift, with larger increases in community care on the one hand, and high-level residential care on the other.

Supply-side adjustments will also be forced by changes in the costs of the different types of aged care.

Community care often relies upon the presence of a co-resident informal carer. ${ }^{17}$ Here somewhat offsetting factors seem likely to operate. As noted above, a diminished gap in life expectancy between men and women is likely to reduce the number of years of widowhood, effectively increasing the supply of co-resident care. On the other hand, as has also been previously noted, the increased numbers who have never married, or who are divorced or separated ${ }^{18}$ will at least partially offset that increase in supply. Additionally, the greater scarcity of working-age people in the future population will also increase the opportunity cost of the choice to engage in informal caring, reducing the supply of informal care services. Finally, low birth rates in recent decades ${ }^{19}$ mean that the average older person will have fewer children from whom informal care can be sought. As a result, and on balance, the supply of informal care is likely to diminish relative to the size of the older population.

Given that demand for community care is likely to increase strongly, reduced supply of informal carers could impose substantial costs on the community-care sector. Already the opportunity cost of informal care, measured as the reduction in paid employment due to caring, has been estimated as being in the order of 0.6 per cent of GDP (that is, about 9.9 per cent of the value of total formal health care). The cost of replacing the work done by informal carers were their services no longer available is, of course, much higher. It has been estimated that if all

\footnotetext{
17 When assessed by Aged Care Assessment Teams, older people living alone are more likely to be recommended for residential care than those living with a spouse or other informal carer. There is also evidence that older people who have access to informal care can remain living in the community for longer and enter residential care at a higher level of frailty. See, for example, Lincoln Gerontology Centre 2002. Projections of the availability of informal care are presented in Australian Institute of Health and Welfare 2004, and National Centre for Social and Economic Modelling 2004.

18 Australian Bureau of Statistics 2007, chapter on Lifetime marriage and divorce trends.

19 Productivity Commission 2008: 34 and 35. The Commission notes that the aged dependency ratio (the proportion of people aged over 65 to people of traditional working age, 15-64) will increase from almost 20 per cent in 2007 to over 42 per cent by 2047. See also Australian Government 2007.
} 
hours of informal care were replaced with services purchased from formal care providers and provided in the home, the replacement value would be about 3.5 per cent of GDP; that is, about 62.2 per cent of other formal health care (Access Economics 2005; Productivity Commission 2003) though there are obvious limits on the relevance of such estimates to the assessment of economic costs.

The difficulties caused by adverse trends in the availability of informal care will be made all the more acute by the fact that the supply of the formal care workforce will also face considerable pressure as the share of the population requiring care increases (Stone and Wiener 2001). In effect, population ageing seems likely to create an increased demand for hospital care, with here too the sheer weight of the numbers moving into the higher age brackets more than offsetting possible reductions in the number of annual hospital bed-days required for each person in each age class. ${ }^{20}$ The resulting growth in total hospital bed-days will require a corresponding increase in the medical labour force, forcing the aged-care sector to compete for nurses and other specialised labour inputs in a tight labour market.

Significant innovations in the way in which services are delivered will be needed if these structural pressures are to be dealt with efficiently. These innovations will affect both the venues in which care services are provided with forms of congregated, but not institutional, living likely to be important in reconciling the need for care with the baby-boomers' demand for independent living - and the manner of service delivery. Widespread diffusion of these innovations will need to be accompanied by shifts in the composition of supply, and most notably, by a re-weighting of supply towards care in the community and the more intensive forms of 'high care'.

Whether the aged-care sector will have the flexibility required to effect these changes remains to be seen. Aged care in Australia developed initially primarily through the charitable sector and, to this day, charitable and non-profit organisations (and state and local governments) account for some 68 per cent of residential places and 95 per cent of community-care packages. While there are many respects in which supply by charitable and non-profit organisations can be a highly effective means of meeting aged-care needs, ${ }^{21}$ there is also evidence

\footnotetext{
${ }^{20}$ While 2005-2050 growth in the number of annual public hospital bed-days is expected to be slightly negative for those under the age of 50 , that number is expected to rise by 150 per cent for the population aged 60 and over, and by 320 per cent for the population aged 85 and over. As a result, the share of hospital bed-days accounted for by the population aged 65 and over is projected to increase from 47 per cent in 2005 to 67 per cent in 2050. See Schofield and Earnest 2006.

${ }^{21}$ It has been claimed, for example, that non-profit institutions may be less likely to opportunistically take advantage of vulnerable clients, so that supply of services by these institutions reduces the extent of the principal-agent problems in situations where clients are not capable of monitoring and enforcing service standards. It is also well-known that the greater the risk of such 'skimping', the more likely it is that the gains from the reduced risk of opportunism outweigh the productive efficiency loss arising from reduced incentives for cost-minimisation associated with non-profit provision: see Hansman 1996. Put slightly differently, the more vulnerable the client population, the greater the role that altruism
} 
that those organisations find it more difficult to undertake supply adjustments (Hansmann, Kessler and McClellan 2002). Thus, their willingness to retrench in a timely way is reduced by the absence of a profit constraint, while their ability to expand is constrained by limited access to equity funding.

\section{Some Proposals for Reform}

The characteristics of aged-care services make it difficult to rely solely on market forces to meet demand. First, given community expectations about the level of care, and also the potential problems of privately insuring against the risk of requiring high-cost aged-care services in the future - which can be economically comparable to private insurance against unpredictable and catastrophic events (Productivity Commission 2008) - there is a need for an effective safety net for those with little ability to pay. Second, as consumers in this industry may be poorly placed to exercise either 'voice' or 'exit', there may be a case for a relatively high degree of service-quality regulation. However, subject to the constraints imposed by such regulation, competition between providers could ensure that the industry adjusted to changing needs, including in terms of the balance between different types and levels of care. Set within a framework of sensible quality regulation, and of provision of a safety net for low-income consumers, market forces could therefore be harnessed to provide individuals with care choices that matched their needs.

Unfortunately, existing regulations of the sector go well beyond what is necessary to achieve social equity, and undermine the ability of market forces to ensure supply effectively meets the needs of consumers. The consequences of the current approach to regulating aged-care services have been extensively discussed in Professor Hogan's Review of Pricing Arrangements in Residential Aged Care (Hogan 2004) and the situation has not altered materially since that time. The most recent development has been the handing down by the Commonwealth Government's consultative body, the National Health and Hospitals Reform Commission (NHHRC), of its Interim Report recommendations, some of which relate to reforms to increase choice in aged care. Nonetheless, existing regulations remain in place. $^{22}$

More specifically, the rationing of places, while it does manage fiscal risk, creates an artificial scarcity that limits the scope for competition, blunts pressures for efficiency and innovation, and deprives consumers of choice.

Thus, since the turn of this century, occupancy levels in residential-care facilities have been in excess of 90 per cent for low care and of 95 per cent for

should play in service provision. As the very elderly, and especially those suffering from impairments such as dementia, are typically unable to monitor and enforce service standards, a significant role for non-profits in service provision may be efficient. A formal model setting this out is in Newhouse 2002.

22 NHHRC 2009. Essentially, its recommendations for aged care mirror those contained in this paper, and are discussed in greater detail below. 
high care, and though they have recently declined slightly, they are likely to stay high for so long as the current planning controls persist. This means that there are usually very few places open in any particular locality. In 2005-2006, for example, in a third of the 71 aged-care planning regions there were (on average) fewer than three vacant places each day for every 1000 people aged 70 or over.

The shortage of places has obvious implications for potential residents and their families. Consumers seeking a place, especially in high care, are often doing so as a result of either a sharp deterioration in the ability to perform essential daily activities or the death of their spouse or carer. There is therefore an element of urgency in their search for a place. Moreover, potential residents (and their families) usually have strong preferences over the location of the facility, and incur a significant element of discomfort should they need to move from one facility to another. Given the urgency of finding a place, and of doing so within a confined geography, persistently high occupancy levels mean that consumers often have very few options open to them.

This, in turn, means that suppliers face little threat of displacement and have limited incentive to be efficient. The result is an industry structure that does not make the best use of scarce resources, leading to losses of allocative, productive and dynamic efficiency.

As at 30 June 2006, some 1276 businesses/organisations ('approved providers') were engaged in the provision of subsidised residential aged care through 2929 outlets ('aged-care homes'). The residential aged-care industry continues to be highly disaggregated, with the average approved provider operating 2.3 aged-care homes and 128.1 operational places in June 2006. Some 65 per cent of providers operate only one home and 71 per cent of providers operate fewer than 100 places.

Many current providers seem too small to achieve economies of scale and scope. However, the restrictions on the number of places make it difficult for entrants to secure a sufficient number of beds in any locality to themselves achieve scale and scope economies and displace less-efficient incumbents. While it is possible that further gains in productive efficiency could be achieved by consolidation among existing providers, with some consolidation having already occurred, ${ }^{23}$ additional efficiency gains might be more readily achieved by making it easier for entrants to grow by establishing new centres, as this would allow them to secure a higher level of standardization and hence reduce costs.

\footnotetext{
${ }^{23}$ For example, roughly 47 per cent of facilities offered more than 40 beds in 1998. By 2007, this had increased to around 66 per cent. The number of facilities with more than 100 beds increased by 121 per cent over the period 1998-2007. See Productivity Commission 2008: 30.
} 
The overall consequence of these restrictions on displacement of existing providers is persistent productive inefficiency. Hogan estimated that in 2001-02, the average technical inefficiency of the residential aged-care industry, measured in terms of the difference between average practice and the technical efficiency frontier, was 17 per cent. It is questionable whether that gap has diminished significantly since then. Thus, industry returns continue to be highly variable. In 2004-05, for example, the average net profit/loss per bed-day varied from a loss of $\$ 7.31$ (or a profit margin of -4.6 per cent of revenue) in the lowest quartile of performance to a profit of $\$ 25.42$ (or a profit margin of +15.9 per cent of revenue) in the highest quartile of performance. While some of these industry returns can be affected by factors unrelated to efficiency, the large gap estimated by Hogan suggests that technical inefficiency is a factor contributing to the inability of a fairly large group of suppliers to achieve cost coverage.

As well as blunting the incentives for technical or productive efficiency, the limited choice most consumers face means that some form of price control is needed to prevent the abuse of localised market power. Reflecting this, most of the prices that can be charged by care providers are set by the Government. ${ }^{24}$ However this in turn leads to further distortions, including allocative inefficiency, as the limited number of places may not be allocated to those who value them most highly. Dynamic efficiency is also reduced because the incentives of operators to make long-term investments in their businesses is blunted by quantity restrictions and hence by uncertainty as to the ability to expand. Additionally, because of price restrictions, there is a longer-term risk that prices will not be allowed to reach levels that cover efficient costs, further compromising the incentives to invest, at least in those locations with high costs of service. The inefficiency created by the rationing of places may then be accentuated by distortions to the pattern of investment, with places ultimately not being available when and where they are needed. The fact that the regulated prices are largely geographically uniform, despite substantial variations in costs, makes these risks of inefficiencies all the greater. ${ }^{25}$

\footnotetext{
${ }^{24}$ The Commonwealth sets the maximum fees that residents can be charged, with the important exception of accommodation bonds, which can only be charged in low care. There are no caps on the amount that can be charged for a bond (except that the resident must be left with a minimum level of assessable assets). In high care, no bonds can be charged (unless the resident is obtaining an 'extra service' room), and the maximum accommodation charge that the resident can be asked to pay is currently $\$ 26.88$ per day. Even in the small 'extra services' segment of the industry - where providers are allowed to charge residents higher prices in return for improved hotel and accommodation services - providers must first have their prices approved by the Department of Health and Ageing and can only change the prices they charge once every 12 months. These legislative requirements are set out in the Aged Care Act 1997 and in the principles made under that Act.

25 For example, cost estimates for the construction of an aged-care home in 2006 varied from between $\$ 90600$ and \$97 700 per place in Adelaide to between \$104 900 and \$113 100 in Brisbane (see Rawlisons 2006). Similarly, nursing wages, which are the most significant drivers of care costs, vary considerably between jurisdictions. For example, as at 1 March 2007, the top pay point for a Registered Nurses Grade
} 
Most recently, the government's own consultative body, the NHHRC (which had access to an earlier form of this article), has commented on and summarised the adverse consequences of quantity restrictions on the various forms of efficiency as follows:

Restrictions on the number of aged care places limit choices for older people. They result in an aged care sector with high occupancy: there is little real opportunity for people to move between aged care services; and people often feel they must take the first available place, rather than wait for their preferred facility, especially if they are waiting for aged care in a hospital. There is little incentive for aged care providers to be entrepreneurial and responsive to older people and their families essentially, they have a 'captive market' — and no matter how well they provide care, they cannot increase their market share simply by attracting a larger number of older people, as they cannot simply expand existing facilities or open new ones due to restrictions on place ... (NHHRC 2009: 171)

The complex structure of the current arrangements has partially disguised these distortions. While there are price controls over all forms of Government-assisted care, the controls over prices for 'low care' residential care are not especially effective, as suppliers are allowed to charge accommodation bonds (upfront payments for admission) that are virtually uncapped. The level of bonds charged has increased substantially over the years (with the average bond increasing by a factor of five in nominal terms over the period 1996-2006), and the value of many bonds now appears to materially exceed the replacement cost of a residential place. ${ }^{26}$ In the last three years, the total value of the accommodation bonds held by the residential-care industry has almost doubled, from $\$ 2.7$ billion to $\$ 5.3$ billion. At the same time, the Government's 'Ageing in Place' policy largely assures residents who enter low-level care of being able to secure a high-level care place as and when their condition deteriorates. Suppliers of low-level care residential care have therefore been pre-selling high-level care and securing what amounts to a largely uncapped pre-payment for high-level care from low-level care bonds. With some 30 per cent of current non-concessional high-level care residents having paid low-level care bonds,

\footnotetext{
1 varies from $\$ 1110.36$ a week in New South Wales to $\$ 963.45$ in South Australia (see Australian Nursing Federation 2007).

${ }^{26}$ In 2007-08, more than half of residents who paid accommodation bonds to secure entry to residential aged care paid a bond worth more than $\$ 150000$. Some 22 per cent of bonds were worth less than $\$ 100000$ and 22 per cent were worth more than $\$ 250000$ (unpublished data for 2007-08 provided by the Australian Department of Health and Ageing). By comparison, the Australian Department of Health and Ageing estimates the average replacement cost of a residential-care place to be in the order of $\$ 150000$ (Australian Department of Health and Ageing 2009a).
} 
there has been a cross-subsidy, or at least a financial transfer, from low-level care to high-level care, mitigating the impacts of the price controls. ${ }^{27}$

Above and beyond the efficiency issues, it is questionable whether the current arrangements are fully sustainable. Through the mechanisms set out above, these arrangements make the financing of high-level care depend, at least in part, on the flow of admissions into (and hence bond payments for) low-level care. However, demographic trends are likely to reduce demand for low-level care relative to high-level care, compromising this source of funding just as the need for high-level care places increases.

Already, recent reforms have rebalanced the supply of subsidised services more towards the provision of community rather than residential care, and (within residential care) towards high-level rather than low-level residential care. ${ }^{28}$ As the trend away from low-level residential care proceeds, the financing of high-level residential care will become increasingly problematic.

Some degree of market response to these pressures is already occurring. More specifically, there appears to be a strong expansion under way in the 'Extra Service' segment of high-level residential care, where prices are less regulated. ${ }^{29}$ These Extra Service homes are allowed to charge bonds, unlike other high-care providers, so that the aggregate charge they impose on residents is less effectively capped. ${ }^{30}$ While Extra Service places have accounted for less than 1 per cent of

${ }^{27}$ In 2007-08, only one-third of aged-care homes that catered predominantly for residents needing high-level care (that is, fewer than 20 per cent of residents receiving low-level care) did not hold any accommodation bonds (unpublished data provided by the Australian Department of Health and Ageing). 28 Originally, the planning arrangements sought to provide 100 aged-care places for every 1000 people aged at least 70. In recent years, provision has been expanded in real terms and is scheduled to reach 113 aged-care places for every 1000 people aged at least 70 by 2011 . Over the last two decades, the planning arrangements have placed greater emphasis on community care. Moreover, all 100 places were originally residential places whereas, under the current arrangements, 25 out of every 113 places are community-care places. The planning arrangements have also been rebalanced to place a slightly greater emphasis on high-level care. Finally, high-level care places were initially planned to account for 40 per cent of all places. Under the current arrangements they are planned to account for 42.5 per cent of all places (Australian Department of Health and Ageing 2009b).

29 The Aged Care Act 1997 (Cth) allows the Department of Health and Ageing to approve 'Extra Service' status for a residential aged-care home, or a distinct part of a home. Extra Service involves the provision of additional 'hotel'-type services or lifestyle extras, including higher standards of accommodation and increased entertainment and food choices. However, aged-care homes are only approved to offer Extra Service if their level of provision of these extras is significantly higher than average. While extra service homes provide a higher level of amenity, the level of care they provide cannot be different from that available in any other residential aged-care home.

30 In general, accommodation bonds are higher in extra-service homes. In 2007-08, the average accommodation bond paid by new extra-service residents was $40 \%$ higher than the average accommodation bond paid by new residents who were not receiving care on an extra-service basis. Extra-service clients also pay an additional extra-service daily fee, with maximum fees approved on a case-by-case basis. The Australian Government's residential-care subsidy to the provider is then reduced by 25 per cent of the daily extra-service fee for that place (the extra-services reduction amount). Providers can recover this reduction from residents. There is very considerable variation in the quantum of these extra-service fees. Thus, while the average fee per bed-day for available places in December 2007 was $\$ 39.28$, there was a substantial cluster of places available in the $\$ 20$ to $\$ 45$ per bed-day bracket. Indeed, 
places in residential aged care, they now account for a substantial share of the recent growth in claim-days. Thus, the number of claim-days in Extra Service increased from around 650000 in the six months to June 2004 to close to 1000000 in the six months to December 2006. The vast bulk of this growth has been accounted for by for-profit providers. Nonetheless, for the six months to December 2006, these providers accounted for 85 per cent of Extra Service claims, while Extra Service claims accounted for 10 per cent of all claims by for-profit providers.

This expansion in Extra Service is all the more remarkable given the fact that the means-testing arrangements for aged-care subsidies tend to penalise residents in Extra Service homes. ${ }^{31}$ Undoubtedly, income and wealth effects are primarily at work, as a more affluent elderly population seeks care better attuned to the amenities it is used to enjoying. As access to these amenities increases the net benefit residents obtain from care (since they value the Extra Service at more than its additional cost), it enhances the efficiency of the aged-care sector as a whole. However, it would be less obviously efficient, and more likely undesirable, were Extra Service to expand simply because it was less constrained than other types of provision - that is, if Extra Service homes could use their relative pricing freedom (in a situation where restrictions on the number of places limit entry and competition) to charge prices durably above costs, while the more effectively price-regulated sector shrank as a result of unduly onerous price controls.

The expansion in Extra Service places cannot, in other words, make up for the lack of competition on the merits between providers and forms of care.

A better arrangement would have three elements.

First, it would reduce, and ultimately remove, controls over the number of places, which would provide more scope for competition and choice.

Second, it would alter the structure of the assistance provided so as to make it more neutral between the venues in which care was provided - that is, so that care in the community (be it domiciliary care or care in congregated living arrangements) could compete on an equal footing with care provided in conventional residential facilities.

\footnotetext{
52 per cent of extra-service places were priced at $\$ 35$ dollars or under per bed-day. However it is the 32 per cent of providers that were charging above $\$ 50$ per bed-day which brings up the average (unpublished data provided by the Australian Department of Health and Ageing).

31 As noted immediately above, under current arrangements, the Commonwealth subsidy payable in respect of a resident in extra service is reduced by 25 per cent of the extra-service fee that the resident pays. Providers are allowed to recoup this reduction from the resident. The net impact is that a resident effectively pays 125 per cent of the extra-service fee (Sections 44-18 and 58-5 of the Aged Care Act 1997).
} 
Third, as those changes came into effect, and competition became a real factor shaping market outcomes, controls over prices could be eased and eventually eliminated, ensuring efficient providers of aged care could fully recover their costs. $^{32}$

While a number of approaches could be adopted to make such a change, there are two reasons why a sensible place to start in terms of significantly expanding capacity (and ultimately removing any restrictions on entry) would be high-level care. This is for two reasons.

First, demand for high-level care is likely to increase over time in response to the demographic changes noted above. Liberalising the supply of high-level care places would therefore be consistent with the patterns that would be observed in an effectively competitive market and would facilitate the transition to such a market.

Second, fiscal risk and, more generally, moral hazard ${ }^{33}$ are less of a concern in high-level care than in other forms of long-term care. High-level care residential care is not desirable for its own sake, and few individuals would choose to consume high-level care merely because it was available at a subsidised charge. ${ }^{34}$ Moreover, to the extent to which there is a concern about fiscal risk, that risk can be managed through the ACAT assessment process (which determines eligibility for care places on the basis of health condition), noting that that process appears to be most effective at the higher levels of impairment.

That said, until significant supply expansion has occurred, localized market power is likely to persist. For this reason, it would be preferable to only gradually ease price controls, contingent upon the development of competition in the industry as other restrictions are removed. This approach is in accord with the recent thinking of the NHHRC which recently stated that:

\footnotetext{
32 This is not to suggest that post-liberalisation prices will be fully efficient. Given product differentiation, this is unlikely (see Arnott and Igarishi 2000). However, the resulting inefficiencies are likely to be very small relative to those of enduring price controls.

33 Moral hazard can be defined as any change in behaviour due to the fact of becoming insured. Moral hazard need not be inefficient: the mere fact that a consumer can only afford to obtain (say) high-care residential care because the costs of that care are covered in whole or in part by the Commonwealth (which therefore acts as an insurer) does not mean that that care is valued at less than its cost (see generally Nyman 2003). However, the term 'moral hazard' is often used to spotlight the prospect of socially costly choices, on account of an insured individual not suffering the full (or any) consequences of decisions they make (and may actually benefit).

34 Put in more technical terms, there are non-pecuniary costs to consuming high care that are not compensated for by the subsidised payments. Note that this does not mean that demand for high care is necessarily completely inelastic to price. It may be that prices charged for high care have an effect on the timing of entry or on the duration of stay, including by affecting the allocation of use as between high-care facilities and alternatives such as hospitals. However, it seems likely that demand would be inelastic at efficient prices (including for the alternative treatment options), so that there is little risk of inefficient moral hazard.
} 
Removing restrictions on the number of aged care places ... should result in increased competition in the provision of aged care, which may extend to price competition. This may enable some cautious relaxation of current constraints on charges for residential care accommodation. There may need to be continued regulation of charges in areas (for example, rural areas) where there are too few providers for there to be a competitive market for provision. (NHHRC 2009: 174).

Ultimately, reform should not be limited to high-level care, at least over the longer term. In particular, community care is the area where the growth in demand is likely to be greatest and it is also an area where there are substantial opportunities to increase efficiency. Moreover, increased availability of community care would, albeit indirectly, place increased competitive pressure on residential-care providers.

Relaxing controls over the number of community-care places is, however, more complicated, as the risks of moral hazard are greater for community care than for other forms of assistance. Experience in the United States and Europe points to a 'woodwork' effect in community care, whereby increased availability of financial support brings carers 'out of the woodwork', increasing budgetary costs without a corresponding increase in the volume of services provided. ${ }^{35}$ Further policy development, aimed at better managing fiscal risk, is therefore needed before a substantial liberalisation of community care can be undertaken across the board. ${ }^{36}$

That risk, however, need not prevent an expansion in the number of community-care places at the upper end of the care spectrum; that is, at the levels of disability corresponding to the current Extended Aged Care at Home $(\mathrm{EACH})$ packages, which provide high-level care nursing services in the home. In effect, the danger of an expansion in the number of places merely displacing care in the home that would have been provided in any event is significantly lower at these high levels of disability.

Such an expansion in EACH packages (and ultimately in community care more generally) would have wider implications for residential-care providers. Specifically, increases in community care create a need for additional access to respite care; that is, for short-duration stays in residential care that serve either

\footnotetext{
${ }^{35}$ For evidence on moral hazard risks in community care in the United States, see Grabowski 2006. For Europe, see Karlsson et al. 2004. There is also evidence of moral hazard in the recent Scottish experience with 'free' (effectively, less-restricted) access to community care - see the increases in expenditure reported in Bell and Bowes 2006. This can be compared with the low incidence of moral hazard in residential care reported in Grabowski and Gruber 2006.

${ }^{36}$ For example, given greater moral hazard, it may be efficient to means test community-care packages more stringently (which would be the equivalent of a higher deductible in an insurance contract). While there are many forms this could take, one would be to provide a matching grant which required a very low level of matching payment by the beneficiary for low levels of outlays and high levels of matching for higher levels of outlays.
} 
to deal with periods where acute care is required or to provide a rest period to carers. Respite care tends to be costlier than longer-duration residential care (inter alia because admission and discharge costs are incurred more frequently), so provision would need to be made for these costs. Moreover, so as to meet this need, providers of residential care would need greater flexibility to use places for respite-care purposes than they currently have. Indeed, an increased emphasis on respite care is one direction current 'low care' providers could take in a more competitive environment.

Over the longer term, care in the community and residential care should be allowed to compete as alternative venues for care provision. For this to occur, the 'care' component of any subsidy provided to residents would need to be effectively separated from the 'accommodation' component, with each of these ultimately becoming portable (so that they can be used for distinct service providers). While reforms in recent years have taken steps in that direction, there remains a considerable distance to go before the subsidies provided come to resemble fully portable and separable vouchers. ${ }^{37}$

This is not to say the current distortions all favour residential care: that is not the case. For example, under current arrangements, means-testing applies to residential services, but not to domiciliary care. A move to a more neutral system would involve not merely a transferable voucher, but one that was subject to the same means-testing (and hopefully to substantially simpler and more transparent means-testing than currently applies) wherever that voucher was ultimately applied. Moreover, it is important that, in contrast to the situation as it stands, the means-testing be the same as between residential and non-residential care options.

There are precedents for use of voucher-like mechanisms in other countries. ${ }^{38}$ Of course, the devil is in the details, and on what terms such vouchers should be made available is a matter of legitimate debate. For instance, in recommending the removal of restrictions on the quantity of aged-care places, the NHHRC has

\footnotetext{
37 One of the central features of the amendments made to the Aged Care Act 1997 by the Aged Care Amendment (2008 Measures No. 1) Act 2008 — the first Act of the Rudd Government — is to clearly separate funding for hotel and accommodation services from funding for care. The new arrangements have also removed extraneous eligibility requirements for concessional treatment (such as pension status) and introduced means-tests that treat pensioners and self-funded retirees with the same level of income or assets equivalently.

Under the new arrangements, funding for hotel and accommodation services is principally the responsibility of residents, who pay a daily accommodation charge (based on their ability to contribute as measured by their assessable assets). Government support for accommodation costs is only paid in respect of those residents who cannot meet their own costs and only paid to the extent to which they cannot meet those costs. (Residents who enter low-level care still have the option to pay an accommodation bond rather than an accommodation charge.) Funding for care, on the other hand, remains principally the responsibility of the Commonwealth, with the resident contributing according to assessable income up to a defined cap.

38 For examples, see Productivity Commission 2008: 116ff.
} 
also advised that providers of aged care would still need to meet existing criteria in order for the care they provide to be eligible for government support, including being an approved provider under the Aged Care Act and having their facilities accredited (NHHRC 2009: 172). Such criteria could be made readily applicable to a voucher scheme.

In short, the current arrangements, while likely relatively effective in providing for equitable access to aged-care services, achieve that goal at what appears to be an unnecessarily high cost. There is a complex tangle of quantitative restrictions that impedes supply flexibility and limits competition. The lack of competition and the desire to limit the Commonwealth's fiscal exposure then give rise to price controls which, though extensive, are of very differing degrees of effectiveness. Consumers face restricted (and distorted) choices in terms of the range of care available, and charges that are often difficult to understand as a result of the interaction of complex prices with even more complex income and assets tests. Recent changes to policy do move broadly in the right direction in addressing these issues; but there remains a need for more comprehensive reform, which by its nature will take some years to devise and effect.

\section{Conclusions}

With or without the reforms suggested above, funding aged care will place a growing burden on the community. Currently, 1.2 per cent of Gross National Income goes on the provision of residential aged-care and community-care packages. Under current policies, public and private expenditure on aged care will more than double, to 2.9 per cent of GNI by 2046-47. ${ }^{39}$

The National Centre for Social and Economic Modelling has projected that there will be a 160 per cent increase in the number of older people needing care over the 30 years from 2001 to 2031 (National Centre for Social and Economic Modelling 2004). As a result, there will need to be increased investment in the construction of aged-care facilities. Currently, aged care accounts for about 5 per cent of all non-residential construction (Australian Bureau of Statistics 2008b). This share can be expected to increase over the next 40 years. There will also be an increased workforce requirement. Currently, the aged-care sector employs about 2 per cent of the workforce. ${ }^{40}$ This share can be expected to double over the next 40 years. Indeed, by 2050, one in 25 workers will be employed in the provision of aged care.

But in itself, this is hardly a concern. Market economies are always restructuring. Today, the communications industry accounts for 2.7 per cent of

\footnotetext{
${ }^{39}$ Estimated by applying the current public/private split of funding (69 per cent/31 per cent) to estimates of public expenditure on residential aged-care and community-care packages. See Australian Government 2007. Similar estimates have been derived by Productivity Commission 2004.

40 Estimate, based on unpublished data provided by the Department of Health and Ageing, Canberra.
} 
Australia's Gross Domestic Product. Thirty years ago that share was 0.8 per cent. A century ago, it would have been much less than that. So, as far as the Australian economy is concerned, the adjustment required to meet the aged-care needs of the ageing population is no greater than has occurred over the last 30 years to meet the increased demand for communication services.

The issues for Government are how to ensure that the economy is able to make this adjustment efficiently, noting that under current policy settings the share of Commonwealth revenues that may need to be spent on aged care will also increase significantly. Currently, the Commonwealth spends about 3 per cent of its revenues on aged care. By 2050, absent significant policy change, this share can be expected to triple, to about 9 per cent.

At the moment, the bulk of aged-care funding is provided by the Commonwealth Government through consolidated revenue. Funding aged care in this way amounts to requiring current tax-payers, who are mainly in the labour force, to pay for the costs of caring for older Australians. The deadweight losses associated with raising this revenue make it all the more important that service provision be as efficient as possible. Moving towards a system that relied more on competitive forces, albeit within limits set by effective service-quality regulation, would help achieve that objective.

\section{References}

Access Economics 2005, 'The Economic Value of Informal Care', report prepared for Carers Australia, Canberra.

Alexander, K. et al. 2001, 'Post-myocardial infarction risk stratification', American Heart Journal 141(1): 37-42. Results: http://www.medscape.com/viewarticle/409246_3

Arnott, R. and Igarishi, M. 2000, 'Rent control, mismatch costs and search efficiency', Regional Science and Urban Economics 30: 249-88.

Australian Bureau of Statistics (ABS) 2008a, Australian Historical Population Statistics, Cat.No.3105.0. 65.001.

2008b, Building Activity, Australia, 8752.0.

2007, Australian Social Trends 2007, 4102.0. at:

http://www.abs.gov.au/AUSSTATS/abs@.nsf/Latestproducts/

26D94B4C9A4769E6CA25732C00207644?opendocument.

Australian Department of Health and Ageing 2009a, 'Supplementary Submission to the Senate Finance and Public Administration Committee Inquiry into Residential and Community Aged Care in Australia', April 2009. 
2009b, 'Submission to the Senate Finance and Public Administration Committee Inquiry into Residential and Community Aged Care in Australia', February 2009.

Australian Government 2007, Intergenerational Report 2007, Treasury.

Australian Institute of Health and Welfare 2004, Carers in Australia: Assisting frail older people and people with a disability, Canberra.

Australian Nursing Federation 2007, Nurses' Paycheck 6(3) (June-August).

Bell, D. and Bowes, A. 2006, Financial care models in Scotland and the UK, Joseph Rowntree Foundation.

Cullen, D. 2007, 'The financial impact of entering aged care', Australasian Journal of Ageing 26(3): 145-7.

Cullen, D. 2003, 'Historical Perspectives: the evolution of the Australian Government's involvement in supporting the needs of older people', Department Of Health and Ageing, Canberra.

Gillick, M. 2006, The Denial of Aging, Harvard University Press.

Grabowski, D. 2006, 'The cost-effectiveness of noninstitutional long term care services: review and synthesis of the most recent evidence', Medical Care Research and Review 63(1): 3-28.

Grabowski, D. and Gruber, J. 2006, 'Moral Hazard in Nursing Home Use', National Bureau of Economic Research, Working Paper no. 11723.

Hansman, H, 1996, The Ownership of Enterprise, Belknap Press of Harvard University Press, Cambridge, London.

Hansmann, H., Kessler, D. and McClellan, M. 2002, 'Ownership form and trapped capital in the hospital industry', NBER Working Paper 8989.

Henderson, A. and Jorm, J. 1998, 'Dementia in Australia', Aged and Community Services Development and Evaluation report No. 35, Department of Health and Ageing, Canberra.

Hogan, W. 2004, 'Review of Pricing Arrangements in Residential Aged Care', Department Of Health and Ageing, Canberra.

Karlsson, M. et al. 2004, 'An International Comparison of Long Term Care Arrangements', Cass Business School, City of London, Faculty of Actuarial Science and Statistics, Actuarial Research Paper No. 156.

Lakdawalla, D. and Philipson, T. 2002, 'The rise in old-age longevity and the market for long-term care', American Economic Review 92: 295-306.

Lakdawalla, D. and Schoeni, R. 2003, 'Is nursing home demand affected by the decline in age difference between spouses?' Demographic Research 8: 279-304. 
Linacre, S. 2006, 'Caring for an Older Australia', Economic and Social Outlook Conference, Melbourne.

Lincoln Gerontology Centre 2002, Aged Care Assessment Program National Minimum Data Set Report, July 2000-June 2001, La Trobe University, Melbourne.

Lindsay, R. et al. 2003, Aged Care Data: Statistical Analysis, ABARE eReport 03.24 .

McCallum, J. 2003, 'Submission to the Inquiry into Long Term Strategies to Address the Ageing of the Australian Population over the Next 40 Years', Parliament of Australia, House of Representatives Standing Committee on Ageing, at sub. no. 132, http://www.aph.gov.au/house/committee/ageing/strategies/subs/subl32.pdf

National Centre for Social and Economic Modelling 2004, 'Who's going to care? Informal care and an ageing population', Report prepared for Carers Australia, University of Canberra, Canberra.

National Health and Hospitals Reform Commission (NHHRC) 2009, 'Interim report - A healthier future for all Australians'.

Newhouse, J. 2002, Pricing the Priceless: A Health Care Conundrum, The MIT Press, Cambridge, London.

Nyman, J. 2003, The Theory of Demand for Health Insurance, Stanford, CA, Stanford University Press.

Productivity Commission 2008, 'Trends in Aged Care Services: some implications', Commission Research Paper, Canberra.

2004, 'Economic Implications of an Ageing Australia', Canberra.

2003, 'Submission to the Review of Pricing Arrangements in Residential Aged Care', Canberra.

Rawlisons 2006, Australian Construction Handbook, Perth.

Reynolds, S., Saito, Y. and Crimmins, E. 2005, 'The impact of obesity on active life expectancy in older American men and women', The Gerontologist 45: 438-44.

Schofield, D. and Earnest, A. 2006, 'Demographic change and the future demand for public hospital care in Australia, 2005 to 2050', Australian Health Review 30( 4): 507-15.

Stone, R. and Wiener, J. 2001, 'Who Will Care For Us? Addressing the Long-Term Care Workforce Crisis', The Urban Institute, at: http://www.urban.org/publications/310304.html. 
US National Institute on Aging, National Institutes of Health, 2002, 'Aging Under the Microscope: A Biological Quest', NIH publication No. 02-2756.

Xie, H., Chaussalet, T. and Millard, P. 2005, 'A continuous time Markov model for the length of stay of elderly people in institutional long-term care', Journal of the Royal Statistical Society 168(1): 51-61. 